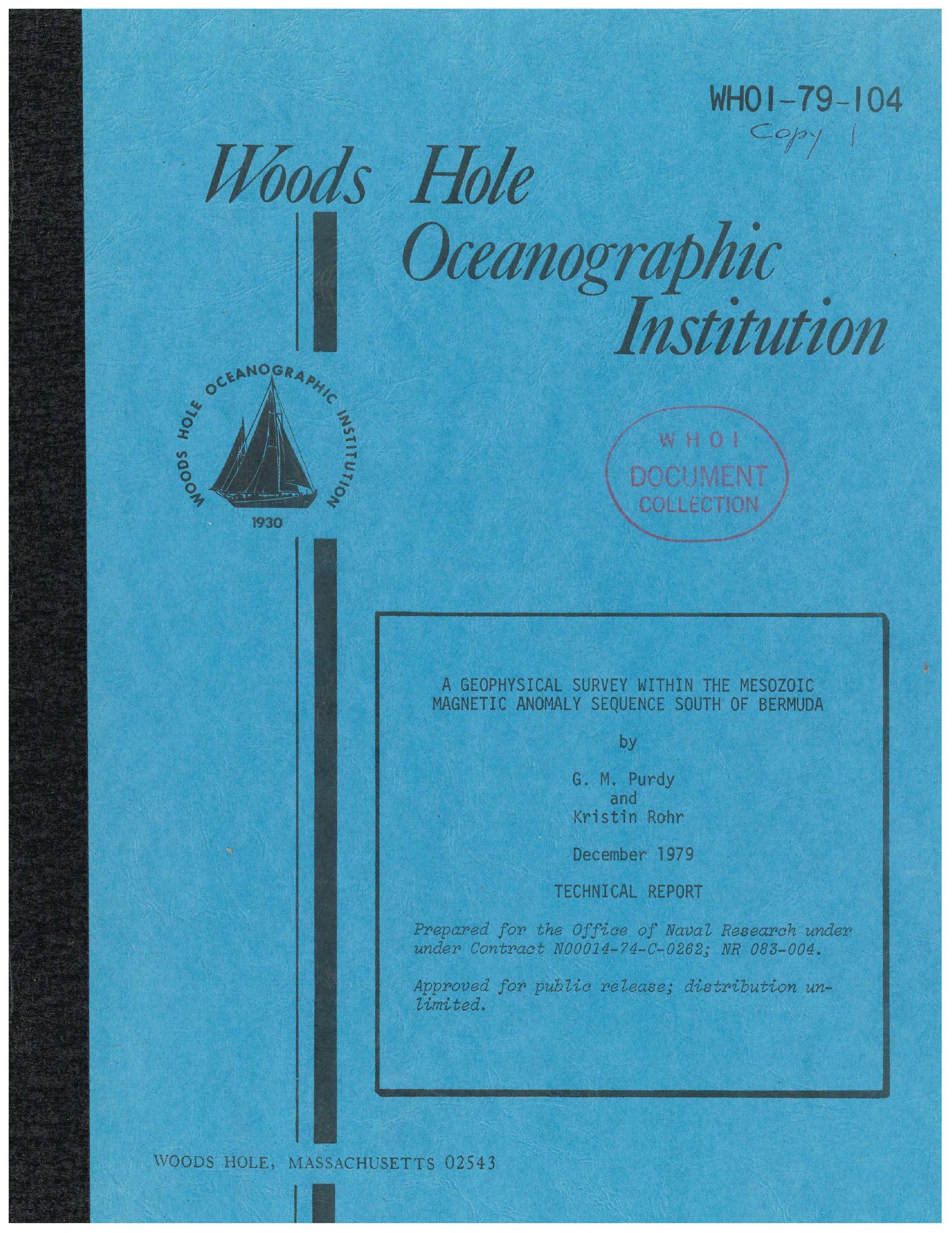


WHOI $-79-104$

A GEOPHYSICAL SURVEY WITHIN THE MESOZOIC MAGNETIC ANOMALY SEQUENCE SOUTH OF BERMUDA

by

G. M. Purdy and

Kristin Rohr

WOODS HOLE OCEANOGRAPHIC INSTITUTION Woods Hole, Massachusetts 02543

December 1979

TECHNICAL REPORT

Prepared for the Office of Naval Research under Contract N00014-74-C-0262; NR 083-004.

Reproduction in whole or in part is permitted for any purpose of the United States Goverment. In citing this report in a bibliography, the reference given should be to "Journal of Geophysical Research, Vol. 84, No. B10, September 10, 1979, pp. 5487-5496".

Approved for public release; distribution unlimited.

Approved for Distribution: John I. Ewing, Chairman Department of Geology \& Geophysics 


\title{
A Geophysical Survey Within the Mesozoic Magnetic Anomaly Sequence South of Bermuda
}

\author{
G. M. Purdy \\ Woods Hole Oceanographic Institution, Woods Hole, Massachusetts 02543 \\ K RISTIN ROHR \\ Woods Hole Oceanographic Institution, Woods Hole, Massachusetts 02543 \\ Massachusetts Institute of Technology, Cambridge, Massachusetts 02139
}

\begin{abstract}
This geophysical survey of an approximate $1^{\circ}$ square covers Mesozoic magnetic anomalies M0, M2, and M4 south of Bermuda. Bathymetry, magnetics, seismic reflection profiling, and seismic refraction data are presented. The isochron trend within the survey area at magnetic anomaly M4 time is $025^{\circ}$. Two left lateral fracture zones exist: the southern fracture zone has an offset of $<10 \mathrm{~km}$ at M4 time and $33 \mathrm{~km}$ at M0 time. The northern fracture zone has an offset of $37 \mathrm{~km}$ at M4 time and $26 \mathrm{~km}$ at M0 time. These changes in offset are accounted for by asymmetric spreading, an $11^{\circ}$ change in trend of anomaly M0 relative to $\mathrm{M} 4$, and by $\mathrm{M} 0$ time, growth of a small right lateral fracture zone. Seismic refraction data provide poor control on the shallow crustal structure but suggest the presence of significant lateral inhomogeneities within layer 2.
\end{abstract}

\section{INTRODUCTION}

We present the results of a detailed geophysical survey in an approximate $1^{\circ}$ square located about $360 \mathrm{~km}$ south of Bermuda (Figure 1). The survey covers Mesozoic magnetic anomalies M0, M2, and M4 [Larson and Hilde, 1975] and was planned as an International Phase of Ocean Drilling (IPOD) site survey. The eastern part of the survey extends into the Cretaceous Quiet Zone.

Bathymetry, magnetics, gravity, and air gun continuous seismic reflection profiling data were collected during cruise 92, leg 1, of R/V Atlantis II. Navigation was by satellite, except in the detailed survey area (box in Figure 1), where a moored radar transponder buoy was used. Two seismic refraction experiments using explosives were carried out with Lamont-type ocean bottom seismometers as receivers [MacDonald et al., 1977]. The results of 14 heat flow measurements taken within the detailed survey area are reported elsewhere (J. Crowe et al., manuscript in preparation, 1979).

The sea floor lies at depths of 4900-5000 m; the many 200 -to 300 -m-high mounds and ridges are not well defined by available data except within the detailed survey area. Two subparallel basement ridges (which in this paper we call East and West ridges; see Figure 1) are the major features; East Ridge has basement relief of about $1 \mathrm{~km}$, a sloping western flank, and a linear eastern facing scarp with a trend of $025^{\circ}$.

\section{TECTONic Framework}

The detailed mapping of magnetic lineations $\mathrm{M} 0, \mathrm{M} 2$, and M4 allows determination of isochron trends, half-spreading rates, and fracture zone locations (Figures 1 and 2). The results of a linear inversion of anomalies M4-M0 along track 5 in Figure 2 is shown in Figure $3 a$ [Schouten et al., 1976]. The magnetization distributions were calculated assuming that observed anomalies were caused by a $0.5-\mathrm{km}$-thick semi-infinite slab situated $5.5 \mathrm{~km}$ below sea level. Using track 5 as a reference, the interpretation of the anomalies on adjacent tracks is a simple matter. The 250- $\gamma$-deep minimum of anomaly M0 is clearly recognized on all tracks except 2,3 , and 9. Anomaly

Copyright (c) 1979 by the American Geophysical Union.
M2 is recognized on tracks 2-9, and M4 on tracks 4-8 (Figure 2).

The identification of anomaly $\mathrm{M} 0$ on tracks 8 and 10 shows that a $33-\mathrm{km}$ left lateral offset exists in the southern part of the survey area (Figure 2). M4 appears to be nearly continuous across this presumed fracture zone. Insufficient data exist south of the fracture zone to define more exactly the magnitude of the M4 offset. Reference to a regional map of magnetic anomalies [Schouten and Klitgord, 1977] shows that at most a $10-\mathrm{km}$ offset can be interpreted. The few suitably located seismic reflection profiles show no linear basement features to help locate this fracture zone more precisely. A $26-\mathrm{km}$ left lateral off set in anomaly M0 exists to the north, between tracks 1 and 4. Although the anomaly is not well defined on track 1 , the identification on track $\mathrm{K} 1$ confirms the presence of this offset. It is not clear whether this is a single off set or a series of at least two, as the M0 trough can be tentatively identified on track 2 , left laterally offset by $13 \mathrm{~km}$ from that on track 4; this pronounced negative anomaly could also be an edge effect caused by the fracture zone. The offset of M4 across this fracture zone is $37 \mathrm{~km}$ [Schouten and Klitgord, 1977].

Figure 1 shows that an eastward extension of the northern fracture zone would cross the East Ridge almost perpendicularly. No disturbance of the reflectors within the sediment column close to East Ridge is observed; therefore it seems improbable that East Ridge was formed by off-ridge tectonic or volcanic activity. Uplift before much sediment had accumulated is a possibility, although crustal blocks either side of a fracture zone are usually decoupled. They probably would not be lifted $1 \mathrm{~km}$ with such a clean scarp; the linearity and trend of the scarp $\left(025^{\circ}\right)$ suggest that this feature is related to a spreading ridge rather than being part of fracture zone mountains or a 'random' seamount massif. Thus we consider it unlikely that the northern fracture zone offset extends through East Ridge and suggest that this section of plate boundary was reorganized soon after M0 time. The 26- $\mathrm{km}$ offset which existed at M0 time may have been destroyed, or the fracture zone may have shifted north by some tens of kilometers.

Within the $65-\mathrm{km}$ wide swath of crust bounded by the northern and southern fracture zones, anomaly M4 has a 


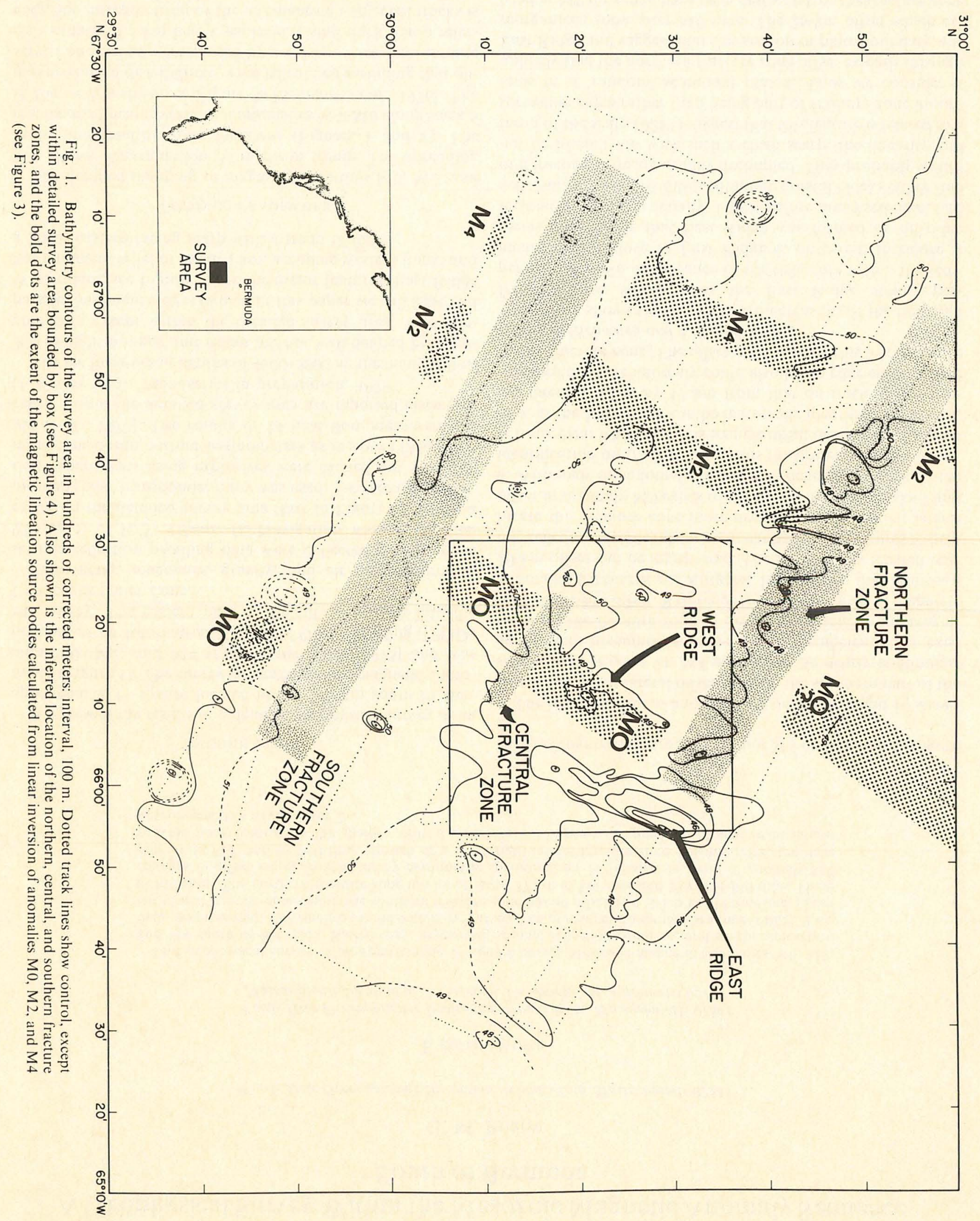




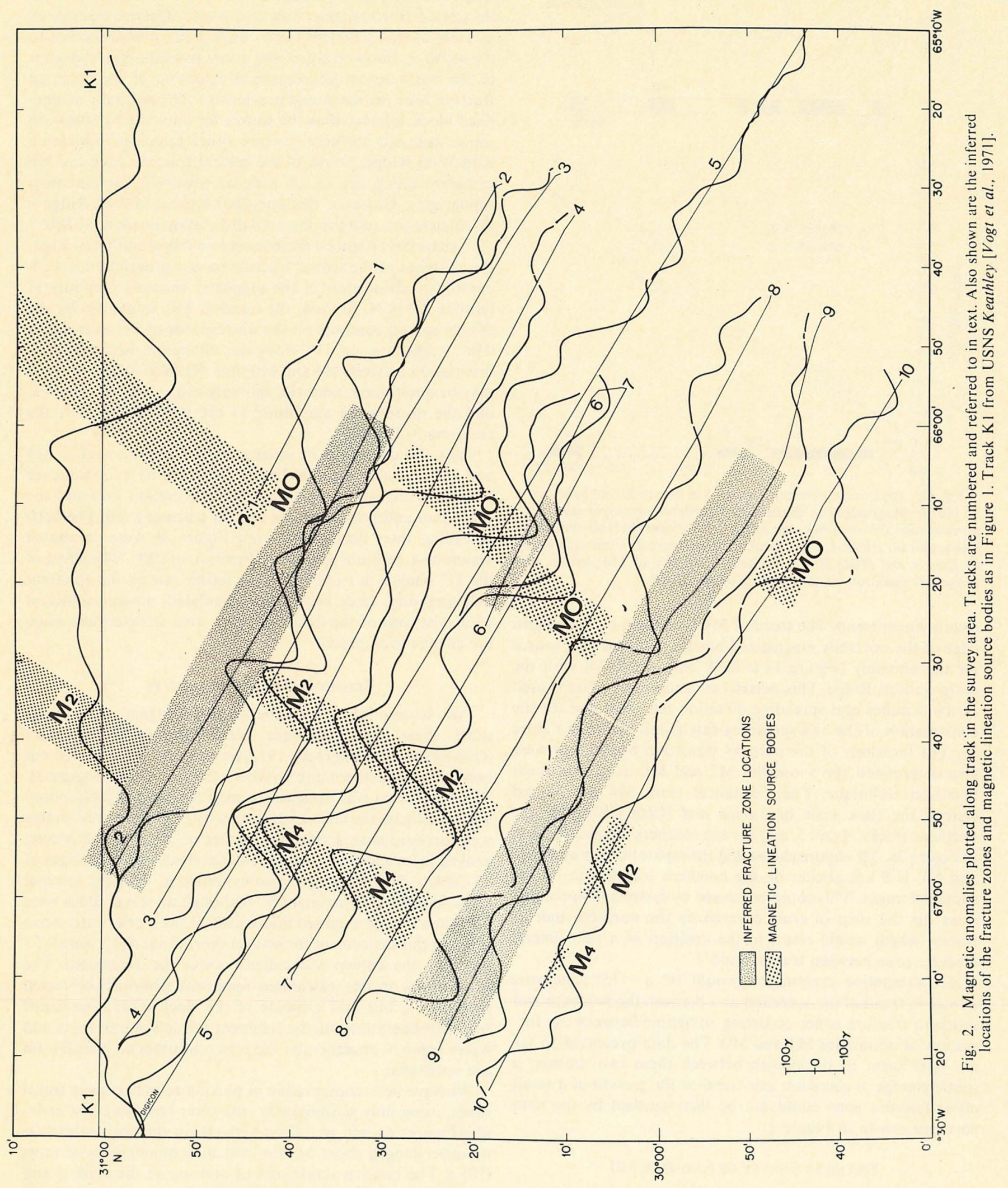



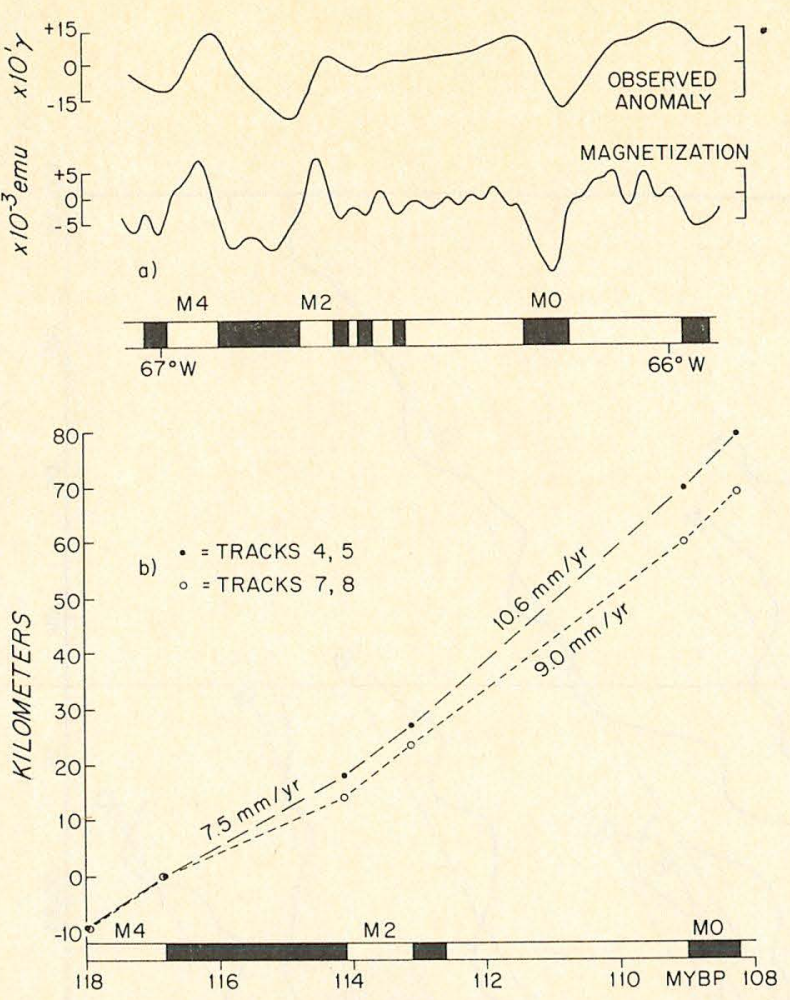

Fig. 3. (a) Linear inversion of track 5 in Figure 2 from $S$ chouten et al. [1976]. Magnetization distribution calculated assuming source is a semi-infinite, $0.5-\mathrm{km}$-thick slab at depth of $5.5 \mathrm{~km}(b)$ Half-spreadingrate graph for tracks 4, 5 and tracks 7, 9 in Figure 2. Time scale is that of Larson and Hilde [1975]. Eastern boundary of M4 defines zero range and lineation trend used to plot this graph.

clearly linear trend. The trend of M4 as defined by the eastern edge of the normally magnetized block calculated as a source for the anomaly (Figure 1 ) is $025^{\circ}$ and is parallel with the scarp on East Ridge. This polarity transition boundary is used as the distance and spreading direction reference line for the construction of the half-spreading-rate graph shown in Figure $3 b$. The locations of the polarity transition boundaries were also determined for anomalies M2 and M0 using the linear inversion technique. Their distances from M4 are plotted against the time scale of Larson and Hilde [1975] for the northern tracks, 4 and 5, and for the southern tracks, 7 and 8 , in Figure $3 b$. This figure shows that the separation between M4 and $\mathrm{MO}$ is $9 \mathrm{~km}$ greater on the northern tracks than on the southern tracks. This could be caused by faster half-spreading rates for the strip of crust covered by the northern pair of tracks, which would result in the creation of a right lateral fracture zone between tracks 5 and 7 .

An alternative explanation would be a $\sim 15^{\circ}$ clockwise change in trend of the accretion axis between the northern and southern fracture zones occurring sometime between the formation of anomalies M4 and M0. The data presented so far are insufficient to distinguish between these two models; a subtle change in accretion axis trend or the growth of a small offset fracture zone could not be distinguished by the data coverage shown in Figure 2.

\section{Detailed Survey of A NOmaly MO}

A detailed survey effort was concentrated on anomaly M0 between the northern and southern fracture zones. Sufficient magnetics and seismic reflection profiling data were collected to allow the construction of well-controlled contour maps of sediment thickness and magnetic anomalies (Figure 4). This figure clearly shows the $250-\gamma$ trough of anomaly M0 offset right laterally at latitude $30^{\circ} 14^{\prime} \mathrm{N}$, implying the existence of a fracture zone between tracks 5 and 7 . We will call this offset the central fracture zone. East and West ridges are manifested as areas of thin sediment cover. Both seem to be truncated to the south by the central fracture zone, and East Ridge extends to the north across any eastward extension of the northern fracture zone (as was noted previously). The normally magnetized block calculated as the source for anomaly $\mathrm{M} 0$ between the central and northern fracture zones coincides in location with West Ridge. South of the central fracture zone the M0 causative block lies in an area of relatively flat basement topography. However, the topographic effect of West Ridge is insufficient to cause the observed dislocation in anomaly M0.

In summary, Figure 4 establishes two important facts. First, the existence of the central fracture zone is proven by the wellcontrolled dislocation in the magnetic anomaly contours at latitude $30^{\circ} 14^{\prime} \mathrm{N}$. Second, the trend of M0, as defined by the closely spaced contours on the western side of the anomaly, is $036^{\circ}$, suggesting an $11^{\circ}$ clockwise change in accretion axis orientation between $\mathrm{M} 4$ and $\mathrm{M} 0$ time. Resolution of this trend may be questioned, since the anomaly exists over a small area, and the decrease in amplitude to the north could shift the contours to the east.

Thus the difference in separation between anomalies M4 and $\mathrm{M} 0$ on tracks 4 and 8 (Figure $3 b$ ) could be a consequence of both a change in the trend of the accretion axis and the formation and growth of the central fracture zone. The halfspreading rates determined from Figure $3 b$ were calculated assuming a constant spreading direction of $025^{\circ}$. The effect of the $11^{\circ}$ change in trend of the accretion axis on the apparent half-spreading rates cannot be calculated, since insufficient data exist west of the detailed survey area to determine when the change took place.

\section{Seismic R EFraction Results}

Two seismic refraction experiments (designated A and B) using three two-component ocean bottom seismometers (OBS's) [MacDonald et al., 1977] as receivers, were carried out between the northern and southern fracture zones (Figure 5). The experiment was designed to map the layer $2 / 3$ boundary and investigate the lateral heterogeneity of oceanic crust in this well-surveyed area. Explosive charges of 5-120 lbs., however, proved insufficient to produce clear arrivals beyond ranges of 15-20 km. Problems were also experienced with the internal clock in OBS 2, experiment B. Although all travel times were corrected for the assumed linear drift of the clock, water wave times to this instrument for several short range shots were $0.5 \mathrm{~s}$ less than the known water depth above the instrument. The travel times on this instrument were thus arbitrarily corrected by $+0.55 \mathrm{~s}$, our best estimate of the clock error determined from considerations of the sediment refraction intercepts and water depth. Consequently, the intercept times on lines B 1-B6 are unreliable.

We have been conservative in picking refracted wave travel times, using only seismograms with clear impulsive first arrivals (Figures $6 a$ and $6 b$ ). First arrivals on the horizontal seismometer lagged those on the vertical component by at most $0.05 \mathrm{~s}$. The relative amplitudes of arrivals on the vertical and horizontal components were variable from shot to shot and instrument to instrument. No systematic relationship between arrival and amplitudes and shot azimuth could be determined on the horizontal seismometer. Second or later arrivals have 

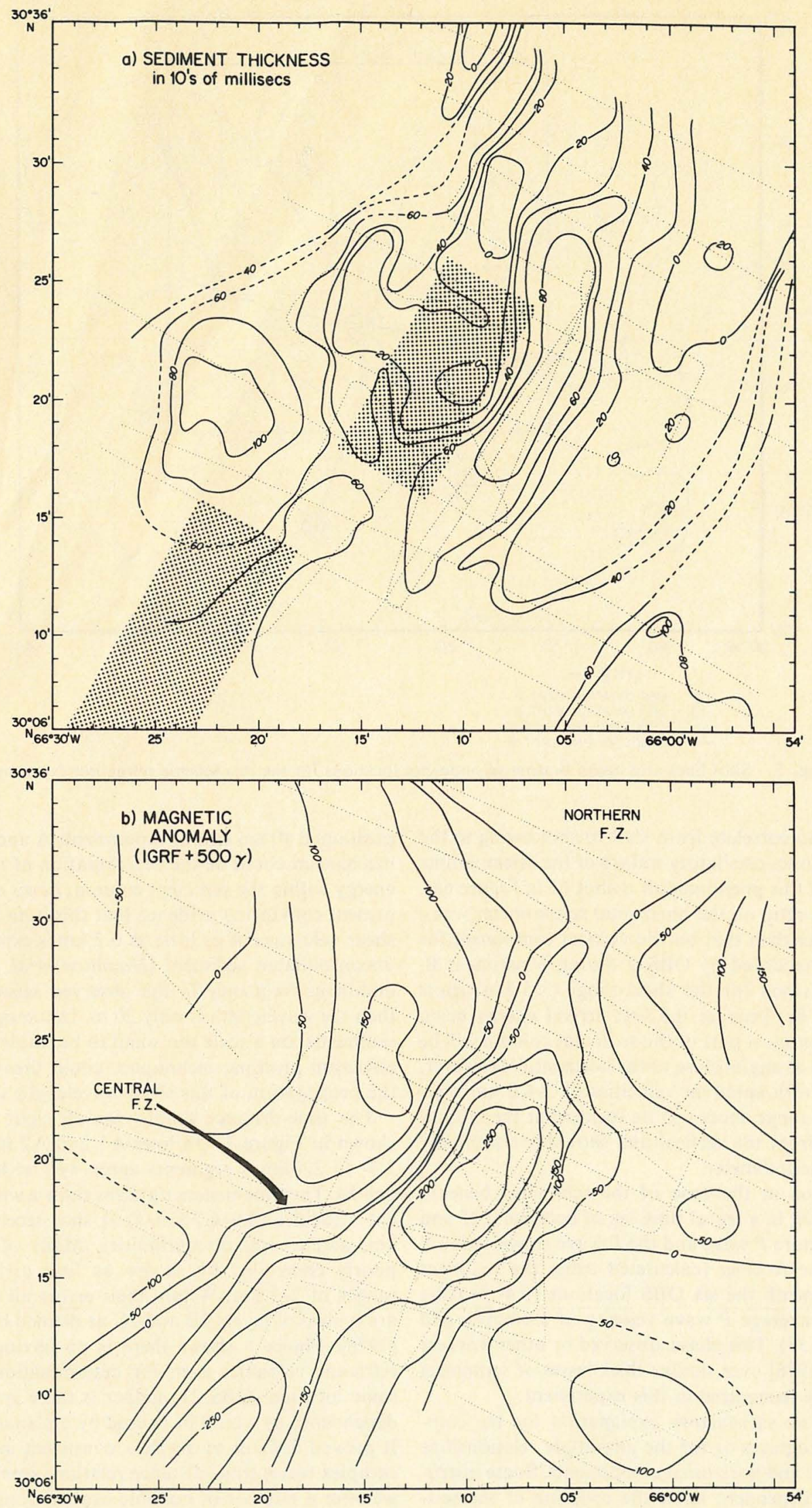

Fig. 4. (a) Contour map of sediment thickness in tens of milliseconds of two-way reflection time (contour interval, 200 $\mathrm{ms}$ ). Dotted tracks show control. Rectangular blocks of dots show inferred location of magnetic source bodies for anomaly M0. The offset between these two blocks overlies West Ridge, and the region to the east with sediment less than $200 \mathrm{~ms}$ thick is East Ridge. (b) Magnetic anomaly contour map of same detailed survey area shown in Figure $4 a$. The $250-\gamma$ troughs are $\mathrm{M} 0$, and the offset caused by the central fracture zone is clearly seen. 


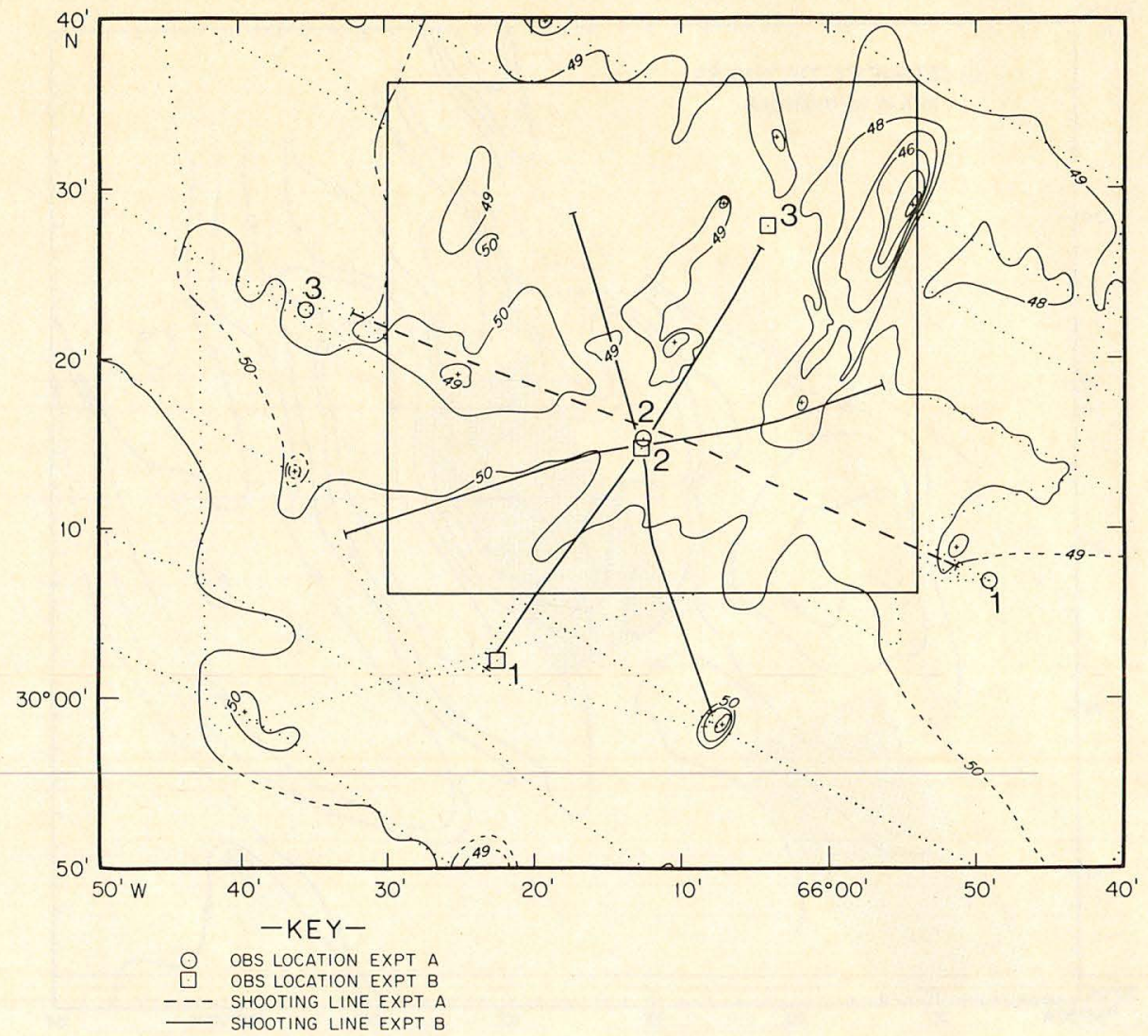

Fig. 5. Shot lines and ocean bottom seismometer locations for the two seismic refraction experiments.

proved impossible to correlate from shot to shot owing to the complex and sometimes oscillatory nature of the seismograms (an extreme case of this phenomenon is shot 61 in Figure $6 a$ ). The signal-to-noise ratio on the horizontal seismometer was a factor of 2-3 greater than that on the vertical component for almost every shot recorded by OBS 2 during experiment B. This can be understood for the short-range $(<5 \mathrm{~km})$ shots (e.g., 61 in Figure $6 a$ ) because the first arrival energy being refracted in the uppermost part of the sediment column will be incident at the OBS at angles close to the horizontal. However, refracted $P$ waves with apparent velocities of $5-6.0 \mathrm{~km} / \mathrm{s}$ received from longer-range shots will be incident at the OBS at angles of $20^{\circ}-30^{\circ}$ from the vertical and should preferentially excite the vertical seismometer.

$P$ to $S$ conversion at the base of the sediments beneath the OBS would result in a travel time lag of between 0.25 and 0.72 s between the pure $P$ wave and the $P$ wave converted to $S$ directly beneath the receiver (calculated using the sediment thickness limits beneath the six OBS locations $(0.4-$ to $0.8-\mathrm{s}$ two-way time), an average $P$ wave velocity of $2.4 \mathrm{~km} / \mathrm{s}$, and Poisson's ratio of 0.35 ). This phase, observed by other workers [e.g., Davis et al., 1976] over similar thicknesses of sediments could not be clearly recognized in this experiment.

We can present no satisfactory explanation for the complexity of the seismograms or for the amplitude relationships between the vertical and horizontal components. Some instrumental resonance, dependent upon the coupling of the seismometers to the unconsolidated surficial sediments, is a plausible theory. This could explain why Ewing and Ewing [1961], using a seismometer attached to a large mass thrust into the upper sediments, recovered clear seismograms with well-defined later arrivals. (Station 2 of Ewing and Ewing [1961] was positioned $40 \mathrm{~km}$ east of experiments A and B.) An alternative mechanism could be the reverberation of trapped shear wave energy within the sediment column. Lewis and McClain [1977] present convincing evidence that this is an important effect. If shear velocities of as little as $0.2 \mathrm{~km} / \mathrm{s}$ exist in the uppermost unconsolidated sediment [Hamilton et al., 1970], and as the dominant frequency in the observed seismograms is $10 \mathrm{~Hz}$, then the wavelength is only $20 \mathrm{~m}$. Inhomogeneities within the sediments, on a scale too small to be resolved by conventional reflection profiling techniques, could then significantly affect the propagation of this short-wavelength shear energy.

The time-distance graphs for all eight shooting lines are shown in Figure 7. On lines A1 and A2 the intercepts of the 2.3 - to $2.4-\mathrm{km} / \mathrm{s}$ segments agree well with the known water depths. The time-distance graphs show a wide scatter of apparent velocities $(4.9-6.7 \mathrm{~km} / \mathrm{s})$ at shot receiver ranges of $5-20$ $\mathrm{km}$, and several discontinuities. Many of the refractors are poorly controlled by as few as four arrivals received over ranges of 2-3 km. Within their errors all observed velocities are typical of layers $2 \mathrm{~B}$ and $2 \mathrm{C}$ as defined by Houtz and Ewing [1976]. Figure 8 shows there is no obvious grouping of the refractor velocities even for determinations recorded at the same location (OBS 2); neither is there systematic azimuthal dependence as would be caused by a planar dipping refractor. It proved difficult to devise a consistent interpretation of the complex travel time-distance relations seen in Figure 7. Below we offer a number of possible explanations.

Sediment thickness variations. Attempts were made to reduce the scatter of travel times by correcting for the 0.5 -s changes in sediment thickness along the shooting lines. Since reflection profiling data were not recorded along the shooting lines, estimates of sediment thickness were made from the 

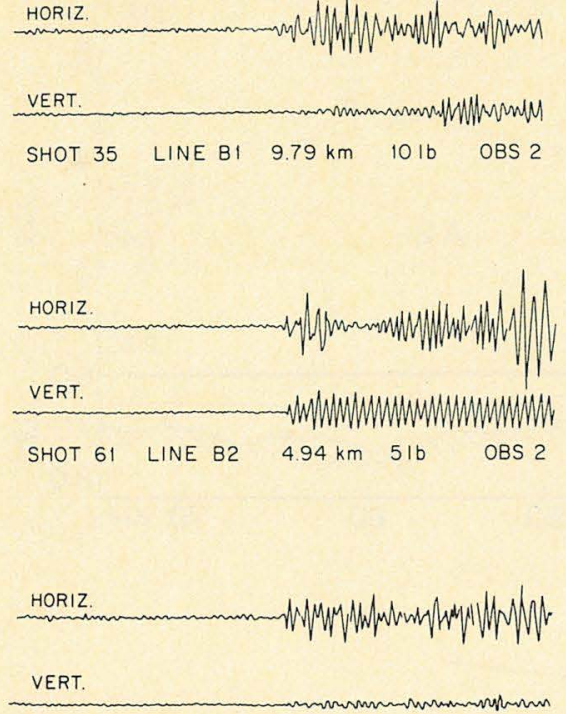

SHOT 131 LINEB3 $9.87 \mathrm{~km} \quad 10 \mathrm{lb}$ OBS 2 ISEC

Fig. 6a. Sample seismograms from OBS 2 experiment B. Note the apparent predominance of energy on the horizontal seismometer on shots 35 and 131 and the striking oscillatory nature of the vertical seismometer on shot 61

contour map (Figure $4 a$ ), yielding travel time corrections of up to $0.3 \mathrm{~s}$. Errors could be introduced into these corrections by undetected small-scale basement topography and by the inadequate knowledge of the velocity structure in the lowermost part of the sedimentary column. Nevertheless, our calculations indicate that variations in sediment thickness cannot satisfactorily explain the discontinuities and the scatter in apparent velocities observed on the time-distance graphs. A qualitative appreciation of this fact can be gained from study of Figure 7, in which basement topography is plotted beneath the timedistance graphs for lines A 1 and A 2; offsets and scatter in the refracted wave travel times do not correlate well with the major basement peaks and troughs.

Sediment velocity variations. The velocity structure of the sediment column is poorly known. The calculated corrections for basement topography mentioned above could be in error if higher-velocity $(3.5 \mathrm{~km} / \mathrm{s})$ sediment existed in the basement troughs. Houtz et al. [1968] found a strong reflector in this region associated with an increase in sediment velocity to 3 $\mathrm{km} / \mathrm{s}$ at the base of the sedimentary column. The strong reflector at a depth of 7.4-s two-way time (between 13 and $25 \mathrm{~km}$ on lines A 1) may represent the top of such a higher-velocity unit (Figure 7). The velocity contrast across the sediment-basement contact could then be reduced to $\sim 1 \mathrm{~km} / \mathrm{s}$; this would partially 'smooth' the basement topography and reduce the contribution of the basement topography to the travel time of the refracted waves to $<0.1 \mathrm{~s}$.

The results of deep drilling, however, do not support this idea [Tucholke, 1978; B. E. Tucholke, personal communication, 1978). The marly limestones and claystones recovered above basement at sites 417, 418 [Shipboard Scientific Party, $1977 a, b$ ], and 386 [Shipboard Scientific Party, 1975] have measured velocities of only $2 \mathrm{~km} / \mathrm{s}$. It seems that only over much older crust to the west of our survey area do the carbonates overlying basement become sufficiently thick and well compacted to affect refracted wave travel times significantly.

Structual discontinuities related to fracture zones. This pos- sibility is difficult to investigate, since much of our data (i.e., travel times recorded by OBS 2 in experiment B) had to be corrected for the clock error mentioned previously. Thus only the relative values of the intercept times are meaningful. However, the difference between the intercepts of the $6.4-\mathrm{km} / \mathrm{s}$ and sediment refractors on line Bl, and a knowledge of the sediment thickness from the seismic reflection data, allows an estimate to be made of the thickness of any unobserved shallow basement layer. Assuming a velocity of $5-5.5 \mathrm{~km} / \mathrm{s}$ for this layer (perhaps layer 2B), situated between the $6.1-$ to $6.4-\mathrm{km} / \mathrm{s}$ refractor and the acoustic basement (as identified on the reflection profiles), this thickness estimate is $200-400 \mathrm{~m}$. A comparable thickness at OBS 2 was determined in a similar way on line A2 using the $2.4-$ and $6.22-\mathrm{km} / \mathrm{s}$ refractor intercepts. Figure 7 shows the intercept of this $6.4-\mathrm{km} / \mathrm{s}$ refractor on line B1 (north of the receiver) to have an intercept $0.3 \mathrm{~s}$ less than the $6.1-\mathrm{km} / \mathrm{s}$ refractor on line B2 (to the south). The $6.4-\mathrm{km} / \mathrm{s}$ refractor on line B6 has an intercept time the same as the 6.1$\mathrm{km} / \mathrm{s}$ refractor on line $B 2$. If these three apparent velocities $(6.4 \mathrm{~km} / \mathrm{s}$ on lines $\mathrm{B} 1$ and $B 6$ and $6.1 \mathrm{~km} / \mathrm{s}$ on $\mathrm{B} 2)$ are associated with the same refractor (layer $2 \mathrm{C}$ perhaps), then the intercept times suggest the presence of a significantly thicker layer 2B on lines B2 and B6. The discontinuity in the travel time plot for line B6 at $8-\mathrm{km}$ range, which may be associated with this structural change, occurs at the location of the central fracture zone. If we again assume a velocity of $5-5.5 \mathrm{~km} / \mathrm{s}$ for the unobserved layer $2 \mathrm{~B}$, then an $\sim 1-\mathrm{km}$ increase in thickness of this layer south of the fracture zone is predicted.

Basement faults or lateral changes in basement velocities. Unreversed slope intercept interpretations of line Al yield sediment thicknesses in agreement with the reflection profiles to better than $0.3 \mathrm{~km}$; thicknesses of the $5.2-\mathrm{km} / \mathrm{s}$ layer are $1.4 \mathrm{~km}$ at OBS 3 and $0.8 \mathrm{~km}$ at OBS 2. The travel times recorded by OBS 2 on line A2 (Figure 7) are significantly
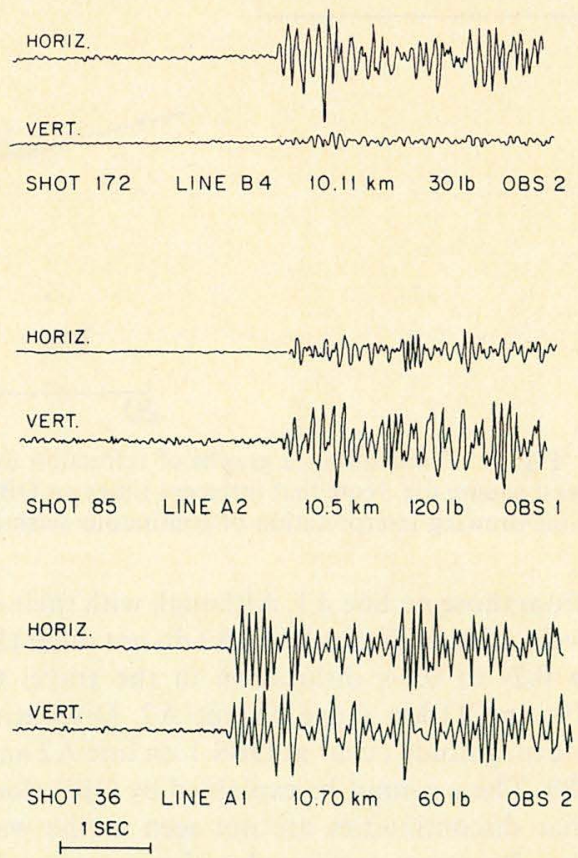

Fig. 6b. Sample seismograms from OBS 1 and OBS 2, experiments $A$ and $B$. Shot 172 shows higher amplitude arrivals on the vertical component than on the horizontal component as seen in Figure $6 a$. Shots 85 and 36 from experiment $A$ do not show this, although for shot 36 , OBS 2 was located only $1 \mathrm{~km}$ north of where it was for shot 35 on line Bl (see Figure $6 a$ ). 

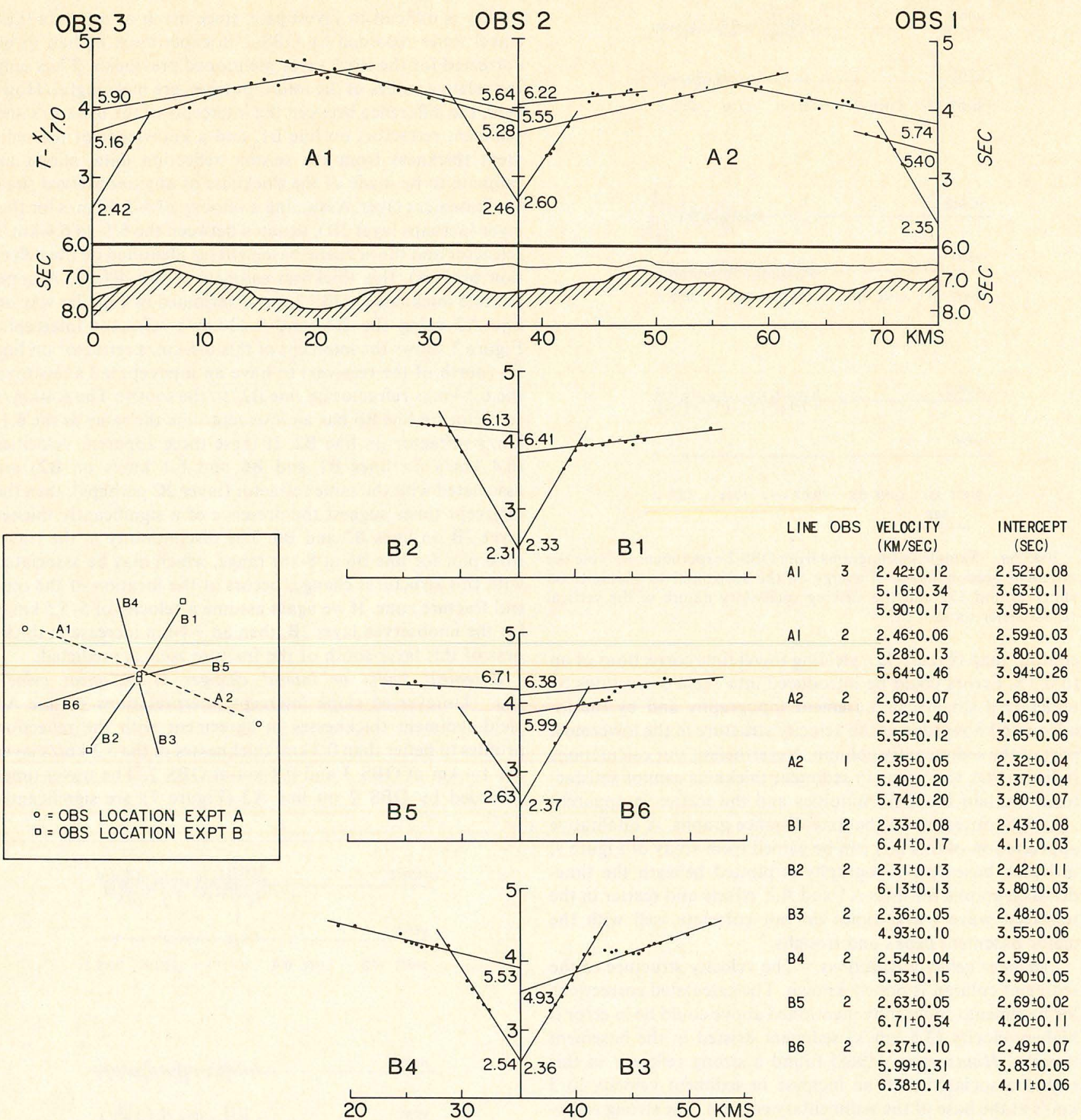

Fig. 7. Time-distance graphs of refraction experiments and velocities and intercepts with their standard errors from least square fits. Note that intercept times on OBS 2 for experiment B have been arbitrarily corrected as discussed in text. Line drawing interpretation of continuous seismic reflection profile is shown beneath lines Al and A2.

different from those on line A1. Although with their errors the apparent velocities on lines A1 and A2 do not differ (Figure 8), there is a 0.2 - to 0.3 -s dislocation in the travel time plot between 10 - and $11-\mathrm{km}$ range on line A2. Discontinuities of comparable magnitude occur at OBS 1 on line A2 and at OBS 2 on line B6. These cannot be explained by OBS clock errors, since similar discontinuities are not seen in the water wave travel times. Basement topography also seems to be an inadequate explanation. We must conclude then that lateral changes in the velocity structure of the basement occur at these locations. Possible changes in basement structure have been discussed simplistically in terms of layers. Strong evidence exists to show that the upper crust is in fact a region of large vertical velocity gradients [e.g., Helmberger, 1977]. Thus the observed structural discontinuities are more realistically represented by lateral changes in velocity gradients than by dislocations in the boundaries of discrete layers.

Lateral variations in velocity gradient can be formed in the crust at the time of its formation by changes in the accretion process or after its formation by differential weathering, heterogeneous patterns of hydrothermal circulation, or tectonic activity. The plate boundary reorganizations that are suggested by our magnetics interpretation could have disrupted the accretion process and may result in the creation of abrupt lateral inhomogeneities in crustal velocity structure.

The results of IPOD drilling on crust of M0 age $500 \mathrm{~km}$ to 
the south of our survey [Shipboard Scientific Party, 1977a, b] show that drill samples recovered from a basement high (site $417 \mathrm{~A}$ ) were pervasively weathered and of a lower velocity (4.2$4.5 \mathrm{~km} / \mathrm{s}$ ) than the relatively fresh basalts recovered nearby from 417D (average velocity, $5.5 \mathrm{~km} / \mathrm{s}$ ). Velocity measurements made in the laboratory by Christensen and Salisbury [1973] have shown that weathering processes can indeed reduce the velocity of basalt samples by up to $1.5 \mathrm{~km} / \mathrm{s}$. The base of the 340 -m-thick sediment column overlying site 417D was dated paleontologically as Aptian-Cenomanian (M0 age). The oldest sediments overlying the basement high at site 417A, however, were dated as Late Cretaceous [Shipboard Scientific Party, 1977a, b]. It is suggested that the sediments ponded in low-lying areas and restricted water circulation within the crust soon after its formation. However, for about $40 \mathrm{~m} . \mathrm{y}$ the basement high on which site $417 \mathrm{~A}$ was located was open to seawater circulation, underwent extreme weathering, and thus is characterized by lower seismic velocities [Shipboard Scientific Party, 1977a, b].

This is strong evidence for the formation of significant $(\sim 1$ $\mathrm{km} / \mathrm{s}$ ) velocity inhomogeneities in the upper crust by differential weathering processes. Such inhomogeneities could be a cause of the nonsystematic variations in basement velocities observed in this work. As these processes tend to reduce the velocity of basement highs in relation to that of the flanking troughs, the systematic effect of basement topography on refracted wave travel times would be reduced. As is observed in this work, corrections for basement topography, assuming laterally uniform basement velocities, would be inadequate to reduce the scatter in travel times.

\section{Discussion AND CONCLUSIONS}

\section{Crustal Structure}

It is clear that the seismic refraction data yielded disappointingly little information on the complex crustal structure of this region. We believe this was due to the following: (1) uncertain apparent velocities poorly constrained by small numbers of identifiable arrivals; (2) unreliable intercept times on OBS 2 due to the internal clock error, (3) inadequate sediment thickness and velocity data with which to calculate precise correc- tions for basement topography, (4) lack of identifiable second and later arrivals because of the 'oscillatory' nature of many of the seismograms, and (5) too few shots being recorded by more than one receiver $(<5 \%)$, a more careful statistical analysis of the travel times (e.g., using the delay time function method of Morris et al. [1969]) thus proving impractical.

We believe that insufficient data exist in the central Atlantic Ocean for us to be justified in classifying as 'anomalous' the complex travel time-distance relations observed in this work and the implied extreme lateral variability in shallow structure. Few refraction experiments of comparable resolving power (using fixed sea floor receivers deployed over a small area and with shot spacings of $<1 \mathrm{~km}$ ) have been carried out.

Our results also suggest that discontinuities in the seismic structure of the crust exist across even small offset fracture zones. The results of other detailed surveys [e.g., MacDonald, 1977] imply that fracture zone separations of $30 \mathrm{~km}$ could be characteristic of much of the central Atlantic Ocean. Thus it is probable that the results of many previous seismic refraction experiments have been contaminated by structural discontinuities associated with small fracture zones. This study illustrates the imperfect view we currently have from seismic refraction data of the structure of oceanic crust.

\section{Evolution}

The magnetics data define well the tectonic evolution of the swath of crust between the northern and southern fracture zones. This evolutionary pattern is shown schematically in Figure 9. At M4 time there existed a linear accretion axis between the two major fracture zones, and the isochron trend is $025^{\circ}$. The offset across the northern fracture zone was 37 $\mathrm{km}$. Between M4 and M0 the offset on the southern fracture zone grew to $33 \mathrm{~km}$ and in the north decreased to $26 \mathrm{~km}$. The average separation of M4 and M0 in the central North Atlantic is $93 \mathrm{~km}$ [Schouten and Klitgord, 1977]. Between the northern and southern fracture zones the separation is $74 \mathrm{~km}$, implying asymmetric spreading. This asymmetric spreading, along with a clockwise rotation of accretion axis, increased the offset across the southern fracture zone by $20-30 \mathrm{~km}$ and decreased the offset of the northern fracture zone by $6 \mathrm{~km}$.

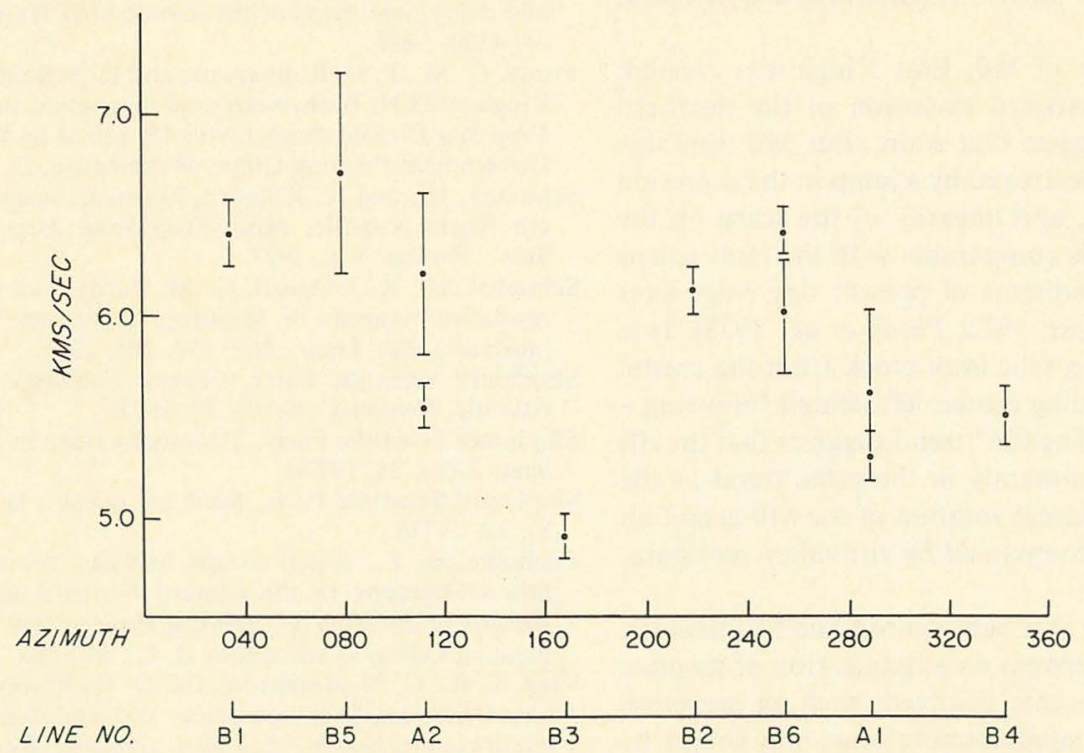

Fig. 8. Apparent velocities (other than sediment velocities) recorded by OBS 2 during both experiments, with their standard error bars, plotted against azimuth of the shot line and shot line number. 


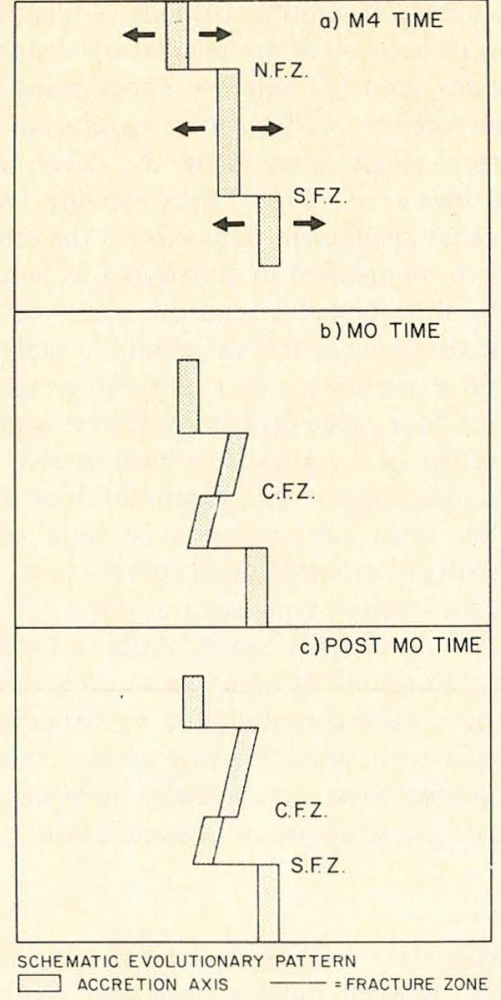

Fig. 9. Inferred schematic evolutionary pattern of area shown in Figure 1. (a) M4 time: presumed orthogonal spreading; the northern (N.F.Z.) and southern (S.F.Z.) fracture zones exist, with offsets of 37 $\mathrm{km}$ and $10 \mathrm{~km}$, respectively. (b) M0 time: clock wise change in trend of accretion axis, and the right lateral central fracture zone (C.F.Z.) has formed. The offsets of the northern and southern fracture zones have changed to $26 \mathrm{~km}$ and $33 \mathrm{~km}$, respectively. (c) Post M0 time: immediately following M0 the northern fracture zone may shift to the north (see text). The accretion axis orientation and continued existence of the central fracture zone at this time are uncertain.

Rotation of the accretion axis was accompanied by formation of a small right lateral fracture zone within the crustal block by M0 time. The formation of the central fracture zone is all the more intriguing because it is the only known right lateral offset in $\mathrm{M} 0$ between latitudes $22^{\circ}$ and $31^{\circ} \mathrm{N}$ [Schouten and Klitgord, 1977].

Following the formation of M0, East Ridge was created; this feature crosses the eastward extension of the northern fracture zone. Thus we suggest that soon after M0 time this off set shifted north or was destroyed by a jump in the accretion axis. The height, steepness, and linearity of the scarp on the eastern side of East Ridge is comparable with the fault scarps observed in the crestal mountains of present day ridge axes [e.g., Bhattacharyya and Ross, 1972; Purdy et al., 1978]. It is possible that East Ridge is a relic fault block from the crestal mountains of the old spreading center, left behind following a jump of the accretion axis. The $025^{\circ}$ trend suggests that the rift valley morphology was dominantly in the same trend as the M4 accretion axis. The apparent rotation of the M0 accretion axis may not have been accompanied by rift valley reorientation.

The magnetics data show that between M4 and M0 time the crustal block surveyed underwent a reorganization of its plate boundaries. Some of the events involved, such as accretion axis rotation or growth of a small fracture zone, may simply be within the statistical error of the physical expression of sea floor spreading processes. These events may contribute to the structural complexities suggested by the seismic data, as may the preferential weathering of topographic highs. Too few such detailed data sets exist over oceanic crust; thus an evaluation of the complexity of our results as typical or anomalous is impossible.

Acknowledgments. We thank the officers, crew and scientific party on board R/V Atlantis II during cruise 92, leg 1, for their expert assistance in collecting these data. This research was supported by the Site Survey Management Office of the International Phase of Ocean Drilling and by the Office of Naval Research. One author (K. R.) received partial support from the Woods Hole Oceanographic Institution Education Program. This manuscript benefited from the critical reviews of Hans Schouten, R. S. Detrick, E. T. Bunce, and John Ewing. Woods Hole Oceanographic Institution contribution 4150.

\section{REFERENCES}

Bhattacharyya, P. J., and D. I. Ross, Mid-Atlantic Ridge near $45^{\circ} \mathrm{N}$, computer interpolation and contouring of bathymetry and magnetics, Mar. Sci. Pap. Il, Infor. Can., Ottawa, Ont., 1972.

Christensen, N. I., and M. H. Salisbury, Velocities, elastic moduli and weathering age relations for Pacific layer 2 basalts, Earth Planet. Sci. Lett., 19, 461, 1972.

Davis, E. E., C. R. B. Lister, B. T. R. Lewis, Seismic structure of the Juan de Fuca Ridge: Ocean bottom seismometer results from the Median Valley, J. Geophys. Res., 81, 3541, 1976.

Ewing, J. I., and M. Ewing, A telemetering ocean bottom seismograph, J. Geophys. Res., 66, 3863, 1961.

Hamilton, E. L., H. P. Burkel, P. O. Keir, and J. A. Whitney, Velocities of compressional and shear waves in marine sediments determined in situ from a research submersible, J. Geophys. Res., 75, 4039, 1970.

Helmberger, D. V., Fine structure of an Aleutian crustal section, Geophys. J. Roy. Astron. Soc., 48, 81, 1977.

Houtz, R. and J. I. Ewing, Upper crustal structure as a function of plate age, J. Geophys. Res., 81, 2490, 1976.

Houtz, R., J. I. Ewing, and X. Le Pichon, Velocity of deep sea sediments from sonobuoy data, J. Geophys. Res., 73, 2615, 1968.

Larson, R. L., and T. W. C. Hilde, A revised time scale of magnetic reversals for the Early Cretaceous and Late Jurassic, J. Geophys. Res., 80, 2586, 1975.

Lewis, B. T. R., and J. McClain, Converted shear waves as seen by ocean bottom seismometers and surface buoys, Bull. Seismol. Soc. Amer., 67, 1291, 1977.

MacDonald, K. C., Near-bottom magnetic anomalies, asymmetric spreading, oblique spreading, and tectonics of the Mid-Atlantic Ridge near latitude $37^{\circ} \mathrm{N}, J$. Geophys. Res., 88, 541, 1977.

MacDonald, W. G., A. C. Hubbard, R. G. Bookbinder, and K. McCamy, Design and shipboard operation of a multipurpose ocean bottom seismograph, Mar. Geophys. Res., 3, 179, 1977.

Morris, G. B., R. W. Raitt, and G. G. Shor, Jr., Velocity anisotropy and delay time maps of the mantle near Hawaii, J. Geophys. Res., 74, 4300, 1969.

Purdy, G. M., P. D. Rabinowitz, and H. Schouten, The Mid-Atlantic Ridge at $23 \mathrm{~N}$ : Bathymetry and magnetics, in Initial Reports of the Deep Sea Drilling Project, vol. 45, edited by W. Melson et al., U.S. Government Printing Office, Washington, D. C., 1978.

Schouten, H., and K. Klitgord, Mesozoic magnetic anomalies, western North Atlantic, Misc. Field Stud. Map MF-915; U.S. Geol. Surv., Reston, Va., 1977.

Schouten, H., K. Klitgord, G. M. Purdy, and C. R. Denham, High resolution analysis of Mesozoic anomalies in the NW Atlantic, (abstract), Eos Trans. AGU, 57, 264, 1976.

Shipboard Scientific Party, Glomar Challenger drills in the North Atlantic, Geotimes, 20(12), 18, 1975.

Shipboard Scientific Party, Mid-ocean ridge in the Cretaceous, Geotimes, 22(6), 21, 1977a.

Shipboard Scientific Party, Studying oceanic layer 2, Geotimes, 22(7, 8), 22, $1977 b$.

Tucholke, B. E., Relationships between acoustic stratigraphy and lithostratigraphy in the western North Atlantic Basin, in Initial Reports of the Deep Sea Drilling Project, vol. 43, U.S. Government Printing Office, Washington, D. C., in press, 1979

Vogt, P. R., C. N. Anderson, and D. R. Bracey, Mesozoic magnetic anomalies, sea-floor spreading and geomagnetic reversals in the southwestern North Atlantic, J. Geophys. Res., 76, 4796, 1971.

(Received May 24, 1978; revised March 22, 1979; accepted April 5, 1979.) 


\section{MANDATORY DISTRIBUTION LIST \\ FOR UNCLASSIFIED TECHNICAL REPORTS, REPRINTS, AND FINAL REPORTS PUBLISHED BY OCEANOGRAPHIC CONTRACTORS \\ OF THE OCEAN SCIENCE AND TECHNOLOGY DIVISION \\ OF THE OFFICE OF NAVAL RESEARCH}

(REVISED NOVEMBER 1978)

1 Deputy Under Secretary of Defense (Research and Advanced Technology) Military Assistant for Environmental Science Room 3D129

Washington, D.C. 20301

Office of Naval Research 800 North Quincy Street

Arlington, VA 22217

3 ATTN: Code 483

1 ATTN: Code 460

2 ATTN: 102B

1 CDR J. C. Harlett, (USN) ONR Representative Woods Hole Oceanographic Inst. Woods Hole, MA 02543

Commanding Officer Naval Research Laboratory Washington, D.C. 20375

6 ATTN: Library, Code 2627
12 Defense Documentation Center Cameron Station Alexandria, VA 22314 ATTN: DCA

Commander Naval Oceanographic Office NSTL Station

Bay St. Louis, MS 39522

1 ATTN: Code 8100

1 ATTN: Code 6000

1 ATTN: Code 3300

1 NODC/NOAA

Code D781

Wiscons in Avenue, N.W. Washington, D.C. 20235 


\begin{tabular}{|c|c|}
\hline REPORT DOCUMENTATION PAGE & $\begin{array}{c}\text { READ INSTRUCTIONS } \\
\text { BEFORE COMPLETING FORM }\end{array}$ \\
\hline $\begin{array}{l}\text { 1. REPORT NUMBER } \\
\text { WHOI }-79-104\end{array}$ & 3. RECIPIENT'S CATALOG NUMBER \\
\hline \multirow{2}{*}{$\begin{array}{l}\text { 4. TITLE (and Subtita) } \\
\text { A GEOPHYSICAL SURVEY WITHIN THE MESOZOIC } \\
\text { MAGNETIC ANOMALY SEQUENCE SOUTH OF BERMUDA }\end{array}$} & $\begin{array}{l}\text { 5. TYPE OF REPORT A PERIOD COVERED } \\
\text { Technical }\end{array}$ \\
\hline & $\begin{array}{l}\text { 6. PERFORMING ORG. REPORT NUMBER } \\
\text { WHOI CON. NO. } 4150\end{array}$ \\
\hline $\begin{array}{l}\text { 7. AUTHOR(e) } \\
\text { G. M. Purdy and Kristin Rohr }\end{array}$ & $\begin{array}{l}\text { 8. CONTRACT OR GRANT NUMBER(a) } \\
\text { N00014-74-C-0262; }\end{array}$ \\
\hline $\begin{array}{l}\text { 9. PERFORMING ORGANIZATION NAME AND ADDRESS } \\
\text { Woods Hole Oceanographic Institution } \\
\text { Woods Hole, MA } 02543\end{array}$ & $\begin{array}{l}\text { 10. PROGRAM ELEMENT, PROJECT, TASK } \\
\text { AREA \& WORK UNIT NUMEERS } \\
\text { NR } 083-004\end{array}$ \\
\hline $\begin{array}{l}\text { 11. CONTROLLING OFFICE NAME AND ADDRESS } \\
\text { NORDA }\end{array}$ & $\begin{array}{l}\text { 12. REPORT DATE } \\
\text { December } 1979\end{array}$ \\
\hline $\begin{array}{l}\text { National Space Technology Laboratory } \\
\text { Bay St. Louis. MS } 39529\end{array}$ & 13. NUMBER OF PAGES \\
\hline 14. MONITORING AGENE Y NAME Q ADDRESS(If dilferent from Controlling Ollice) & $\begin{array}{l}\text { 15. SECURITY CLASS. (of this roport) } \\
\text { UnClaSS ified } \\
\text { 15. DECLASSIFICATION/DOWNGRADING } \\
\text { SCHEDULE }\end{array}$ \\
\hline
\end{tabular}

Approved for public release; distribution unlimited.

17. DISTRIBUTION STATEMENT (of the ebatract ontered in Block 20, If differont from Roport)

18. SUPPLEMENTARY NOTES

Reprinted from "Journal of Geophysical Research, Vol. 84, No. B10, September 10, 1979, pp. 5487-5496".

19. KEY WORDS (Conthue on sevorse side if nocessery and Identtly by block number)

1. Geophysical survey

2. Magnetics and seismics

3. South of Bermuda

20. ABSTRACT (Continue on reverse olde if neceecery and ldentily by block number)

This geophysical survey of an approximate $7^{0}$ square covers Mesozoic magnetic anomalies M0, M2, and M4 south of Bermuda. Bathymetry, magnetics, seismic reflection profiling, and seismic refraction data are presented. The isochron trend within the survey area at magnetic anomaly $M 4$ time is $025^{\circ}$. Two left lateral fracture zones exist; the southern fracture zone has an offset of $₹ 10 \mathrm{~km}$ at $M 4$ time and $33 \mathrm{~km}$ at $M 0$ time. The northern fracture zone has an offset of $37 \mathrm{~km}$ at M4 time and $26 \mathrm{~km}$ at MO time. These changes (Cont. on back) 
in offset are accounted for by asymmetric spreading, an $11^{\circ}$ change in trend of anomaly $M 0$ relative to M4, and by MO time, growth of a small right lateral fracture zone. Seismic refraction data provide poor control on the shallow crustal structure but suggest the presence of significant lateral inhomo geneities within layer 2. 


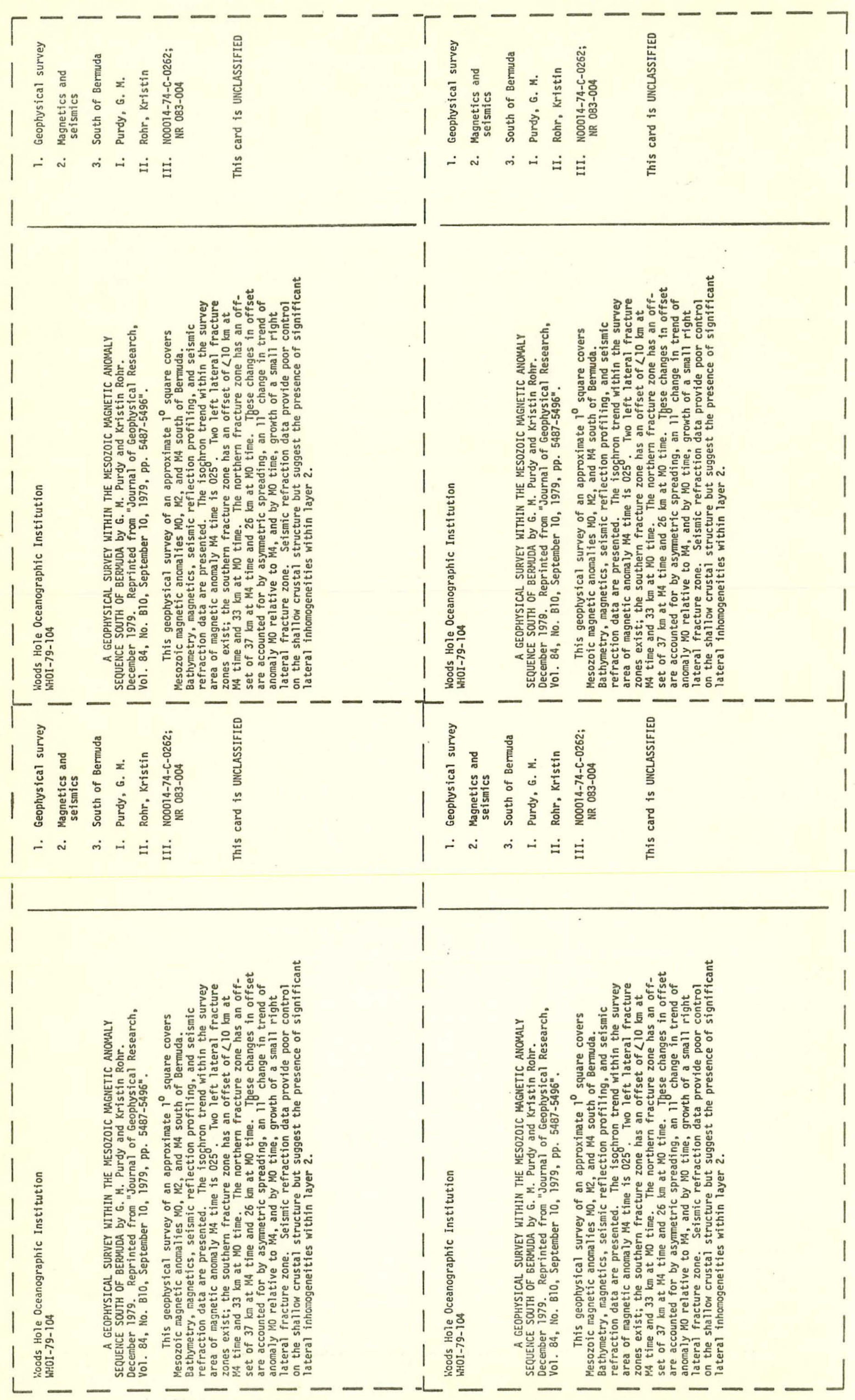

